\title{
Role of calcium ions in the pressure control of renin secretion from the kidneys
}

\author{
Holger Scholz, Marlies Hamann, Karl-Heinz Götz, Armin Kurtz \\ Institut für Physiologie I, Universität Regensburg, Universitätsstrasse 31, D-93040 Regensburg, Germany
}

Received September 27, 1993/Received after revision February 14, 1994/Accepted March 10, 1994

\begin{abstract}
In this study we examined the role of calcium ions in the control of renin release by the renal artery pressure. For this purpose renin secretion rates (RSR) were measured in isolated rat kidneys perfused at pressures of $140,100,80$ and $40 \mathrm{mmHg}[19,13,11,5 \mathrm{kPa})$ with media containing either $1.5 \mathrm{mmol} / \mathrm{l}$ ("normal") or zero calcium concentrations (calcium-free perfusate with $0.5 \mathrm{mmol} / \mathrm{l}$ EGTA). At normal calcium the RSR was inversely related to the renal artery pressure, whereas calcium withdrawal resulted in an almost linear and proportional relationship between RSR and perfusion pressure. As a consequence, RSR at $140 \mathrm{mmHg}(19 \mathrm{kPa})$ with a calcium-free medium was similar to renin release at $40 \mathrm{mmHg}(5 \mathrm{kPa})$ with normal calcium. The nitric oxide (NO) donor sodium nitroprusside $(1 \mu \mathrm{mol} / \mathrm{l})$ stimulated RSR in a pressure-dependent fashion at a calcium concentration of $1.5 \mathrm{mmol} / \mathrm{l}$. With a calcium-free perfusate, sodium nitroprusside did not restore the inverse pressure dependence of RSR seen with normal calcium but almost doubled the RSR across the whole pressure range. Whilst RSR was significantly reduced by angiotensin II $(1 \mathrm{nmol} / \mathrm{l})$ in the range between $40 \mathrm{mmHg}$ and $140 \mathrm{mmHg}(5-19 \mathrm{kPa})$ with normal calcium, withdrawal of extracellular calcium ions practically abolished the inhibitory action of angiotensin II. Since angiotensin II attenuated RSR especially at low renal perfusion pressure, our results indicate that renin release in this pressure range is still inhibitable by calcium mobilization in renal juxtaglomerular cells. Thus, the enhancement of renin secretion at lower pressures cannot be explained by a decreased sensitivity of renin release towards calcium ions. Instead, our data support the hypothesis that the "baroreceptor" control of renin secretion is maintained through a pressure-related calcium influx mechanism into juxtaglomerular cells which counteracts the stimulatory effect of locally released NO.
\end{abstract}

Correspondence to: H. Scholz, Institut für Physiologie I, Universität Regensburg, Postfach 101042, Universitätsstrasse 31, D-93040 Regensburg, Germany
Key words: Renal baroreceptor - Juxtaglomerular cells - Isolated kidneys - Angiotensin II - Nitric oxide

\section{Introduction}

A local "baroreceptor" mechanism in the wall of the afferent arterioles is considered to adjust renin release from juxtaglomerular cells to the renal artery pressure [7]. On the basis of circumstantial evidence, Fray has developed a mathematical model suggesting stretch-dependent influx of extracellular calcium ions into juxtaglomerular cells to account for the pressure control of renin secretion $[4,5]$. In detail, an increase of the renal artery pressure would enhance circumferential stretch of the juxtaglomerular cells thereby causing membrane depolarization with subsequent calcium influx through voltage-operated calcium channels [4]. Since a rise of the intracellular calcium concentration is considered to be an inhibitory signal for renin secretion from these cells [7], this hypothesis would explain how renin release is negatively linked to renal artery pressure. More direct experimental approaches such as patch-clamp studies [10] and experiments on isolated glomeruli [12] failed to support a role of voltage-operated $\mathrm{Ca}^{2+}$ channels in the pressure-mediated control of renin secretion [20]. In addition, recent observations have demonstrated that endothelium-derived relaxing factor/nitric oxide (EDRF/NO) is required for the normal relationship between renal perfusion pressure and renin release [19, 21]. Since EDRF formation is strongly calcium-dependent [13] any manoeuvre modulating transmembrane calcium entry into endothelial cells would affect EDRF release. Thus, the baroreceptor control of renin secretion could be simply maintained by a pressure-dependent release of local EDRF. Fray's stretch-receptor hypothesis and, in particular, the relevance of calcium influx into 
juxtaglomerular cells for the pressure regulation of renin secretion may therefore be challenged.

In view of the above it appeared reasonable to us to reconsider thoroughly the role of calcium ions in the "baroreceptor" control of renin secretion. Since changes of the plasma calcium concentration cannot be performed reproducibly in intact animals, we used a model of isolated perfused rat kidneys, which is characterized, similar to the kidney in vivo, by a typical, inverse relationship between perfusion pressure and renin secretion rates $[20,21]$.

The findings obtained with this preparation suggest that the pressure control of renin secretion results from the interaction between tonically released NO $[9,21]$ and pressure-dependent calcium entry into juxtaglomerular cells rather than being maintained through changes in the calcium sensitivity of renin release.

\section{Materials and methods}

Male (250-350 g body weight) Sprague Dawley rats (Charles River, Sulzfeld, Germany), kept on a normal sodium diet, were used throughout. Kidney perfusion was performed in a recycling system according to the technique of Schurek and Alt [24] with minor modifications as described in detail previously $[20,22]$. In brief, animals were anaesthetized with $150 \mathrm{mg} \mathrm{kg}^{-1}$ thiobutabarbitone (Inactin, Byk Gulden, Konstanz, Germany). Volume loss during preparation was corrected by intermittent injections of $0.9 \%$ saline (about $2.5 \mathrm{ml}$ total) via a catheter inserted into the jugular vein. After the abdominal cavity had been opened by a mid-line incision, the right kidney was exposed and placed in a thermoregulated metal chamber. Following intravenous heparin injection ( $2 \mathrm{U}$ $\mathrm{g}^{-1}$; Braun, Melsungen, Germany) the aorta was clamped distal to the right renal artery and the large vessels branching off the abdominal aorta ligated. A double-barrelled cannula was inserted into the abdominal aorta and placed close to the origin of the right renal artery. After ligation of the aorta proximal to the right renal artery the aortic clamp was quickly removed and perfusion was started in situ with an initial flow rate of $8 \mathrm{ml} \mathrm{min}{ }^{-1}$. The kidney was excised and perfusion at constant pressure $(100 \mathrm{mmHg}$; $13 \mathrm{kPa}$ ) was established. The renal artery pressure was monitored by a strain-gauge transducer (P23Db, Statham, Puerto Rico) and the pressure signal used for feedback control of a peristaltic pump. The perfusion circuit was closed by draining the renal venous effluent via a metal cannula back into a reservoir $(200-220 \mathrm{ml})$. The basic perfusion medium, which was taken from the thermostated $\left(37^{\circ} \mathrm{C}\right)$ reservoir, consisted of a modified Krebs-Henseleit solution containing (in $\mathrm{mmol} / \mathrm{l}$ ) $140 \mathrm{Na}^{+}, 5.0 \mathrm{~K}^{+}, 1.5 \mathrm{Ca}^{2+}$, $2.0 \mathrm{Mg}^{2+}, 120 \mathrm{Cl}^{-}, 27.5 \mathrm{HCO}_{3}^{-}$and $0.7 \mathrm{HPO}_{4}^{2-}$. The perfusate was enriched with all physiological amino acids in concentrations between $0.2 \mathrm{mmol} / \mathrm{l}$ and $2.0 \mathrm{mmol} / \mathrm{l}$ and contained in addition (in $\mathrm{mmol} / \mathrm{l}) 8.7$ glucose, 0.3 pyruvate, $2.0 \mathrm{~L}$-lactate, 1.02 -oxoglutarate, $1.0 \mathrm{~L}$-malate, 0.15 creatinine and 6.0 urea. The perfusion medium was supplemented with $60 \mathrm{~g} / 1$ bovine serum albumin, $10 \mathrm{mU} /$ [Lys $^{8}$ ]vasopressin and with freshly washed human red blood cells (10 $\pm 2 \%$ haematocrit). Ampicillin $(30 \mathrm{mg} / \mathrm{l})$ and flucloxacillin $(30 \mathrm{mg} / \mathrm{l})$ were added to inhibit bacterial growth. To improve the functional preservation of the preparation, the perfusate was continuously dialysed against a 25 -fold volume of medium of the same composition but lacking erythrocytes and albumin. For oxygenation of the perfusion medium, the dialysate was equilibrated with a prewarmed and moistened gas mixture containing $94 \% \mathrm{O}_{2}$ and $6 \% \mathrm{CO}_{2}$. Perfusate flow rates were determined from the revolutions of the peristaltic pump, which was calibrated before each experiment. Renal perfusion rate and pressure were continuously monitored on a potentiometric recorder (REC 102, Pharmacia LKB, Bomma, Sweden). Stock solutions of the drugs to be tested were dissolved in freshly prepared dialysate and infused into the arterial limb of the perfusion circuit directly before the kidneys at exactly $1 \%$ of the rate of perfusate flow (perfusor adapted from Fresenius, Oberursel, Germany). For determination of perfusate renin activity, aliquots (about $0.2 \mathrm{ml}$ ) were taken at 2min intervals from the arterial limb of the circulation and from the renal venous effluent respectively. The samples were centrifuged $\left(4^{\circ} \mathrm{C}\right)$ at $1500 \mathrm{~g}$ for $15 \mathrm{~min}$ in a bench-top centrifuge (Eppendorf 5413 , Hamburg, Germany) and the supernatants subsequently assayed for renin activity.

Calcium-free perfusion. Withdrawal of extracellular calcium during the experiments was performed by a rapid exchange of the standard dialysate $\left(\mathrm{Ca}^{2+} 1.5 \mathrm{mmol} / \mathrm{l}\right)$ against a nominally calciumfree one containing $0.5 \mathrm{mmol} / 1$ [ethylenebis(oxonitrilo)] tetraacetic acid (EGTA). Assuming a $K_{\mathrm{d}}$ value for EGTA of $150 \mathrm{mmol} / 1$ [8], this manoeuvre was calculated to reduce extracellular calcium concentrations to the nanomolar range.

Determination of renin activity. Perfusate samples were incubated for $1.5 \mathrm{~h}$ at $37^{\circ} \mathrm{C}$ with plasma from bilaterally nephrectomized male rats as a renin substrate [11]. The generated angiotensin I (AngI) was determined by radioimmunoassay (Sorin Biomedica, Düsseldorf, Germany).

Renin release. Since renin is not inactivated during its passage through isolated perfused rat kidneys [22], renin secretion rates (RSR) could be calculated from the arteriovenous differences of perfusate renin activity and the corresponding renal perfusion rates.

Agents. Pyruvate was obtained from Boehringer-Mannheim, Mannheim, Germany. Flucloxacillin was from Beecham, Bern, Switzerland. Glutamate, urea, sodium acetate, sodium nitrate and 2-oxoglutarate were obtained from Merck, Darmstadt, Germany, L-Malic acid and L-lactate as sodium salts were obtained from Serva, Heidelberg, Germany. L-Amino acids were from Braun, Melsungen, Germany (Aminoplasmal, 5\% paediatric, free of carbon hydrate). Ampicillin, sodium nitroprusside, [Lys $\left.{ }^{8}\right]$ vasopressin, angiotensin II, EGTA and bovine serum albumin (fraction V powder) were purchased from Sigma, Deisenhofen, Germany.

Statistics. Experiments were normally performed in such a way that a single preparation was first used as a control and then for the experimental protocol. If not otherwise indicated, a total of five different kidney preparations was used for each group. Statistical significance was calculated by one-way analysis of variance followed by Scheffe's test. $P<0.05$ was considered significant. Data are quoted as means \pm SEM.

\section{Results}

Isolated rat kidneys were perfused for $90 \mathrm{~min}$ throughout. Within this period perfusate flow rates remained stable and were $14.5 \pm 0.5 \mathrm{ml} \mathrm{min}{ }^{-1} \mathrm{~g}^{-1}(n=10)$, the corresponding RSR was $3.5 \pm 0.5$ (ng AngI h${ }^{-1}$ ) $\min ^{-1} \mathrm{~g}^{-1}$ at a renal artery pressure of $100 \mathrm{mmHg} ; 13 \mathrm{kPa}$ (Fig. 1 ). To test for pressure dependence of renin release the perfusion pressure was adjusted stepwise to $140,100,80$ and $40 \mathrm{mmHg}(19,13,11,5 \mathrm{kPa})$. As shown in Fig. 2 the resulting curve for RSR was characterized by a plateau phase with RSR inhibited at pressures higher than $100 \mathrm{~mm} \mathrm{Hg}(13 \mathrm{kPa})$. Lowering the renal artery pressure below $100 \mathrm{mmHg}(13 \mathrm{kPa})$ caused RSR to increase exponentially to $42 \pm 4\left(\mathrm{ng}\right.$ AngI h$\left.{ }^{-1}\right) \min ^{-1} \mathrm{~g}^{-1}(n=10)$ at $40 \mathrm{mmHg}(5 \mathrm{kPa})$. Decreasing the perfusion pressure from 140 to $40 \mathrm{mmHg}$ (19 to $5 \mathrm{kPa}$ ) resulted in a more 


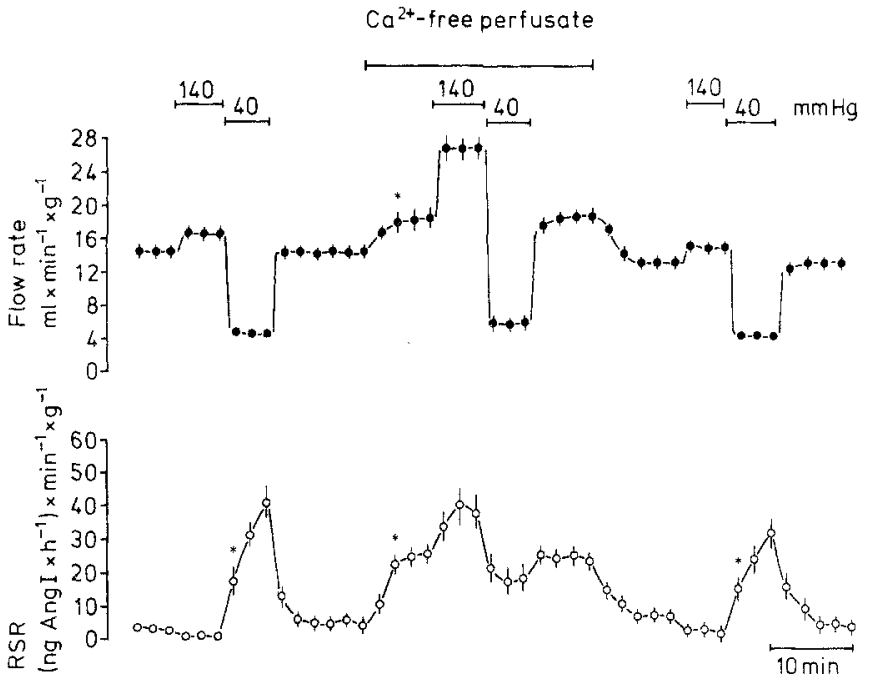

Fig. 1. Renal flow (upper trace) and renin secretion rates (lower trace) at $1.5 \mathrm{mmol} / \mathrm{l}$ (normal) calcium concentrations and with a nominally calcium-free perfusate containing $0.5 \mathrm{mmol} / \mathrm{I}$ EGTA. Under control conditions the perfusion pressure was held at $100 \mathrm{mmHg}(13 \mathrm{kPa})$ and from this value it was changed in a single pressure step as indicated. Values are means \pm SEM of ten experiments. Asterisks indicate that the first values in the sequence are significant compared to their respective controls $(P<0.05)$

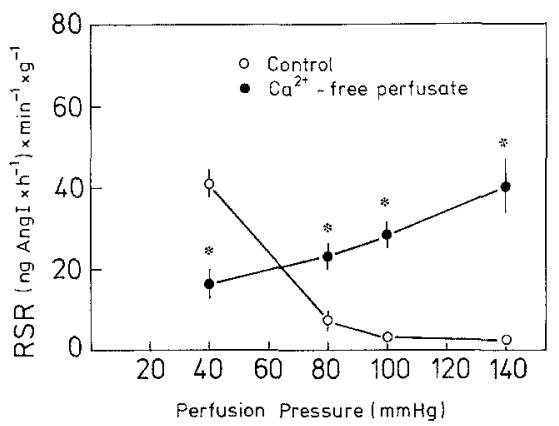

Fig. 2. Pressure-dependent renin secretion from isolated kidneys perfused with media containing either $1.5 \mathrm{mmol} / \mathrm{l}$ or zero calcium ions. Values are means \pm SEM of five kidney preparations. Asterisks indicate significance compared to respective controls with $1.5 \mathrm{mmol} / \mathrm{l} \mathrm{calcium}(P<0.05)$

than 15-fold enhancement of RSR. The rise in RSR was of rapid onset and readily reversible within $5 \mathrm{~min}$ after readjusting the pressure at $100 \mathrm{~mm} \mathrm{Hg} ; 13 \mathrm{kPa}$ (Fig. 1).

Withdrawal of calcium by a rapid exchange of the standard dialysate $\left(\mathrm{Ca}^{2+} 1.5 \mathrm{mmol} / \mathrm{l}\right)$ for nominally calcium-free medium containing $0.5 \mathrm{mmol} / \mathrm{l}$ EGTA caused renal perfusion rates to increase to $18.5 \pm 1.5 \mathrm{ml}$ $\min ^{-1} \mathrm{~g}^{-1}(n=10)$ and also reversibly enhanced RSR to $25 \pm 3\left(\mathrm{ng} \mathrm{AngI} \mathrm{h}^{-1}\right) \mathrm{min}^{-1} \mathrm{~g}^{-1}$ at $100 \mathrm{~mm} \mathrm{Hg} ; 13 \mathrm{kPa}$ (Fig. 1). Calcium-free perfusion abolished the characteristic reciprocal relationship between perfusion pressure and renin release; increasing the renal artery pressure under these conditions resulted in a practically linear and proportional increase of RSR to $40 \pm 7$ (ng AngI $\left.\mathrm{h}^{-1}\right) \min ^{-1} \mathrm{~g}^{-1}(n=5)$ at $140 \mathrm{mmHg} ; 19 \mathrm{kPa}$ (Fig. 2, Table 2).

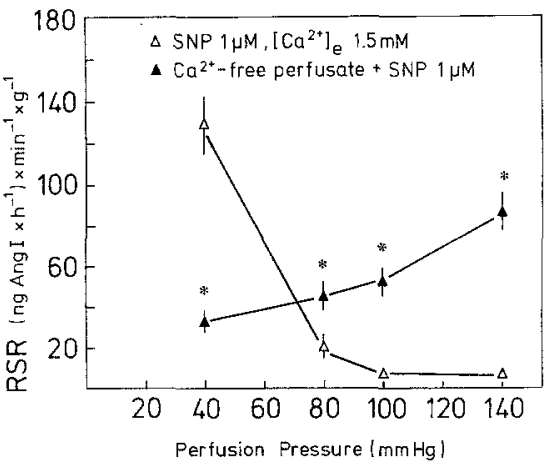

Fig. 3. Effect of the nitric oxide liberator sodium nitroprusside $(S N P, 1 \mu \mathrm{mol} / 1)$ on pressure-related renin release at normal calcium and with a calcium-free perfusate. Values are means \pm SEM of five experiments each. Asterisks indicate significance compared to respective control values with $1.5 \mathrm{mmol} / \mathrm{l}$ extracellular calcium $(P<0.05)$

Table 1. Pressure-dependent renin secretion rates under control conditions and with $1 \mu \mathrm{mol} / 1$ sodium nitroprusside

\begin{tabular}{|c|c|c|}
\hline \multirow{2}{*}{$\begin{array}{l}\text { Perfusion } \\
\text { pressure } \\
(\mathrm{mmHg})\end{array}$} & \multicolumn{2}{|c|}{$\begin{array}{l}\text { Renin secretion rate } \\
{\left[\left(\text { ng AngI } h^{-1}\right) \min ^{-1} \mathrm{~g}^{-1}\right]}\end{array}$} \\
\hline & control & $\begin{array}{l}\text { sodium } \\
\text { nitroprusside }\end{array}$ \\
\hline 40 & $42 \pm 4$ & $129 \pm 14 *$ \\
\hline 80 & $7.5 \pm 1.5$ & $20 \pm 5^{*}$ \\
\hline 100 & $3.5 \pm 0.5$ & $8.0 \pm 2.5^{*}$ \\
\hline 140 & $3.0 \pm 0.5$ & $3.5 \pm 0.5$ \\
\hline
\end{tabular}

Values are means \pm SEM of five kidney preparations

* Significant compared to respective control without sodium nitroprusside $(P<0.05)$

As shown in Fig. 3, the NO donor [16] sodium nitroprusside $(1 \mu \mathrm{mol} / \mathrm{l})$ enhanced RSR with normal calcium and this stimulatory effect was markedly more pronounced in the lower pressure range than at high pressure values (Table 1 ). Thus, $1 \mu \mathrm{mol} / \mathrm{l}$ sodium nitroprusside increased RSR from the control value of $42 \pm 4$ (ng AngI h${ }^{-1}$ ) $\min ^{-1} \mathrm{~g}^{-1}$ (Fig. 2) to $129 \pm 14$ (ng AngI h ${ }^{-1}$ ) $\min ^{-1} \mathrm{~g}^{-1}$ at $40 \mathrm{mmHg} ; 5 \mathrm{kPa}(n=5)$, whilst having no significant effect at $140 \mathrm{mmHg} ; 19 \mathrm{kPa}$ (Fig. 3, Table 1). Sodium nitroprusside $(1 \mu \mathrm{mol} / \mathrm{l})$ also enhanced RSR from kidneys after calcium withdrawal. In contrast to the finding with normal calcium, the stimulatory effect of sodium nitroprusside with a calcium-free perfusate was independent of the perfusion pressure (Fig. 3, Table 2). Exogenous NO obviously did not restore the inverse pressure dependence but approximately doubled RSR across the whole pressure range (Table 2).

To test the possibility that increased RSR at low perfusion pressure only resulted from a decreased sensitivity to inhibitory calcium ions, angiotensin II was used to mobilize calcium in vascular smooth muscle and juxtaglomerular cells [10]. In the presence of normal calcium angiotensin $I I(1 \mathrm{nmol} / \mathrm{l})$ promptly and reversibly reduced perfusate flow rates from $14.5 \pm 0.5 \mathrm{ml} \mathrm{min}{ }^{-1} \mathrm{~g}^{-1}$ 
Table 2. Pressure-dependent renin secretion rates with a calciumfree perfusate in the absence and presence of $1 \mu \mathrm{mol} / \mathrm{l}$ sodium nitroprusside

\begin{tabular}{lll}
\hline $\begin{array}{l}\text { Perfusion } \\
\text { pressure } \\
(\mathrm{mmHg})\end{array}$ & $\begin{array}{l}\text { Renin secretion rate } \\
{\left[\left(\mathrm{ng} \mathrm{AngI} \mathrm{h} \mathrm{min}^{-1}\right) \mathrm{min}^{-1} \mathrm{~g}^{-1}\right]}\end{array}$ \\
\cline { 2 - 3 } & $\begin{array}{l}\mathrm{Ca}^{2+} \text {-free } \\
+ \text { sodium } \\
\text { nitroprusside }\end{array}$ \\
\hline 40 & $16 \pm 4$ & $31 \pm 3^{*}$ \\
80 & $23 \pm 3$ & $44 \pm 5^{*}$ \\
100 & $25 \pm 3$ & $54 \pm 6^{*}$ \\
140 & $40 \pm 7$ & $87 \pm 8^{*}$ \\
\hline
\end{tabular}

Values are means \pm SEM of five kidney preparations

* Significant compared to respective control without sodium nitroprusside $(P<0.05)$
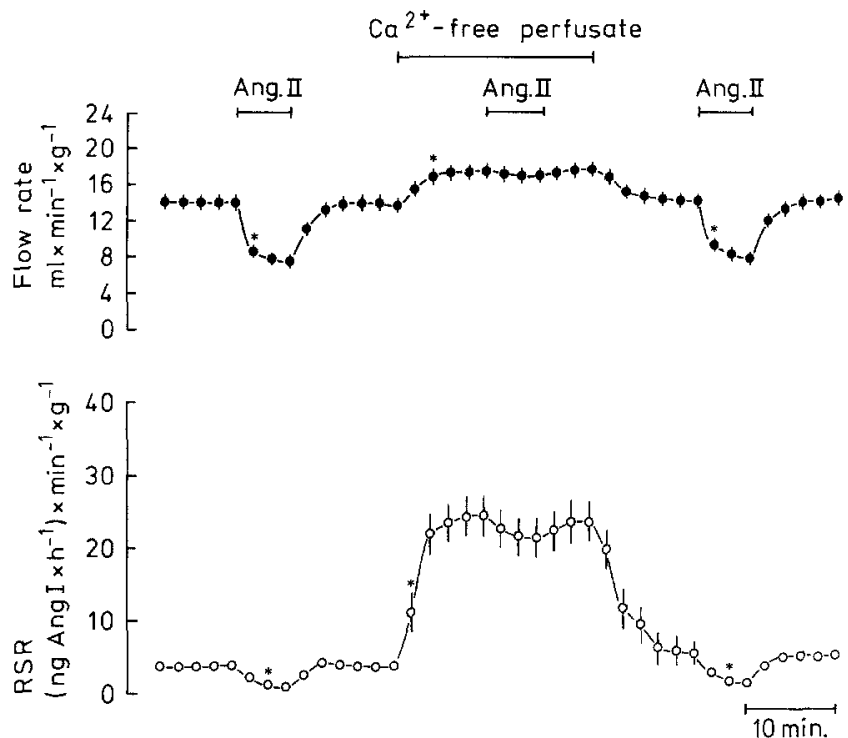

Fig. 4. Calcium dependence of the vasoconstricting (upper) and renin-inhibitory (lower) effect of angiotensin II (Ang. II) in isolated perfused kidneys. Angiotensin II was applied at a final concentration of $1 \mathrm{nmol} / \mathrm{l}$ by continuous infusion directly before the renal artery. Perfusion pressure was kept at $100 \mathrm{mmHg}(13 \mathrm{kPa})$. Values are means \pm SEM of five experiments. Each asterisk indicates the first value in the sequence being significantly different from its respective control $(P<0.05)$

to the minimum value of $7.5 \pm 0.5 \mathrm{ml} \mathrm{min} \operatorname{mog}^{-1} \mathrm{~g}^{-1}(n=5)$ and this vasoconstriction was accompanied by a significant inhibition of basal RSR (Fig. 4). After calcium withdrawal the vasopressor action of angiotensin II was abolished and the decrease of renin release markedly attenuated (Fig. 4). Since the inhibitory action of angiotensin II on renin secretion was thus dependent on extracellular calcium (Fig. 4), we used this peptide to examine whether calcium mobilization in juxtaglomerular cells is dependent on the perfusion pressure. As shown in Fig. 5, angiotensin II markedly decreased RSR at $140 \mathrm{mmHg}$ and $100 \mathrm{~mm} \mathrm{Hg}$ (19 and $13 \mathrm{kPa}$ ) and this inhibitory effect became even more apparent at lower renal artery

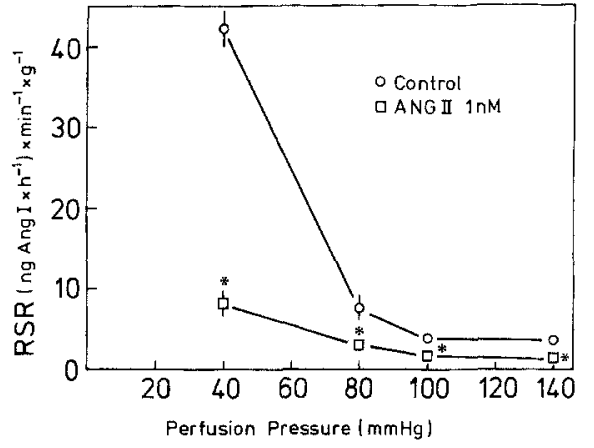

Fig. 5. Effect of angiotensin II ( $A N G I I, 1 \mathrm{nmol} / \mathrm{l})$ on renin secretion rates from kidneys perfused at different renal artery pressures with an extracellular medium containing $1.5 \mathrm{mmol} / 1 \mathrm{calcium}$. Values are means \pm SEM of five experiments each. Asterisks indicate significance compared to controls without angiotensin II $(P<0.05)$

pressures. For comparison, RSR at $40 \mathrm{mmHg}(5 \mathrm{kPa})$ was $42 \pm 4$ (ng AngI $\mathrm{h}^{-1}$ ) $\mathrm{min}^{-1} \mathrm{~g}^{-1}$ under control conditions and $7.5 \pm 2.5$ (ng AngI $\mathrm{h}^{-1}$ ) $\mathrm{min}^{-1} \mathrm{~g}^{-1}$ with $1 \mathrm{nmol} / \mathrm{l}$ angiotensin II (Fig. 5).

\section{Discussion}

In this study we have examined the role of calcium ions in the control of renin secretion by the renal artery pressure. For this purpose we used a model of isolated perfused rat kidneys which has previously been found to release renin in a characteristic pressure-dependent fashion [20]. Compared with the in vivo kidney, isolated perfused kidney preparations offer the advantage that calcium ions can be removed from and reintroduced into the extracellular fluid, thus allowing the role of calcium in the pressure modulation of renin release to be studied under controlled in vitro conditions [22].

Our finding that withdrawal of calcium ions from the perfusate stimulated renin secretion (Fig. 1) is in good agreement with a number of in vivo and in vitro observations $[1,4,5]$ suggesting that an increase of cytoplasmic calcium concentration acts as an inhibitory signal for renin release from renal juxtaglomerular cells. The latter phenomenon is commonly referred to as the calcium paradox of renin secretion (cf. [7]).

Notably, the characteristic inverse pressure dependence of renin release changed to a positive linear relationship after calcium withdrawal (Fig. 2). This finding is consistent with the view that the perfusion pressure inhibits renin secretion through a calcium-dependent signal transduction mechanism $[4,5]$. Since withdrawal of calcium ions blunted the myogenic control of renal vascular tone, resulting in a linear correlation between renal artery pressure and perfusion rates (Fig. 1), our findings could indicate that blood flow through the kidneys acts as a stimulus for renin release which is normally overridden by the calcium-dependent inhibitory influence of the renal perfusion pressure.

In this regard it might be argued that the inverse pressure dependence of renin secretion may simply have 
resulted from a decreased calcium sensitivity of juxtaglomerular cells at lower pressures. To examine this possibility we tested the effect of angiotensin II, which mobilizes calcium ions in afferent arteriolar smooth muscle and juxtaglomerular cells [10]. Our results (Fig. 4) confirm that a calcium influx mechanism is important not only for the vasoconstriction but also for the renin-inhibitory action of angiotensin II $[1,26]$. At normal extracellular calcium concentration, however, renin secretion was significantly attenuated by angiotensin II across the whole pressure range (Fig. 5) suggesting that calcium mobilization in renal juxtaglomerular cells and its inhibitory effect on renin release were independent of the renal artery pressure. In conclusion, pressure-dependent changes of the calcium sensitivity of juxtaglomerular cells appear not to be involved in the baroreceptor control of renin secretion.

Accumulating evidence suggests that endotheliumderived relaxing factor/nitric oxide (EDRF/NO) [18] is a potent stimulus for renin release in vivo $[17,19]$ and in vitro $[6,15,21,23]$. In particular, EDRF/NO has been reported to account for the substantial part of renin secretion which is stimulated by low renal artery pressure [21]. On the basis of findings with isolated perfused rat kidneys [21] we have recently hypothesized that the renal baroreceptor for renin secretion consists of at least two components: EDRF, which is tonically released from the juxtaglomerular apparatus [9] and may stimulare renin secretion, and a second, renin-inhibitory mechanism which is positively linked to the perfusion pressure and overrides the stimulatory effect of EDRF at higher pressures. Such a concept is extended by our present results showing that the NO donor sodium nitroprusside [16] stimulated RSR in a pressure-regulated fashion with normal extracellular calcium but failed to restore any characteristic of the relationship between perfusion pressure and renin release after calcium removal (Fig. 3). Thus, our findings are consistent with the idea that a mechanism of transmembrane calcium entry participates in pressure-mediated inhibition of renin secretion $[4,5]$.

Withdrawal of calcium ions from the perfusate of isolated kidneys decreases calcium influx not only into juxtaglomerular but also in vascular smooth muscle (VSMC) cells. Transmembrane calcium entry into VSMC occurs mainly through voltage-operated calcium channels, which are considered to be essential for the myogenic control of vascular tone [14]. Our previous findings with L-type calcium channel antagonists also support a role for such channels in the autoregulation of renal blood flow [22]. These drugs, however, did not change the inverse relationship between perfusion pressure and renin release [22]. Taking this into account along with our present results one may therefore conclude that renal vascular pressure modulates renin secretion through a transmembrane calcium influx pathway that is distinct from a voltage-operated $\mathrm{Ca}^{2+}$ channel. Recent studies suggest that VSMC respond to membrane stretching with calcium entry through a dihydropyridineinsensitive mechanism [3]. The relevance of stretch-activated ion channels has also been considered for the myo- genic regulation of vascular resistance $[3,14]$. Since juxtaglomerular cells reversibly differentiate from VSMC $[2,25]$, one could speculate from our findings on whether the pressure control of renin release is mediated by a similar mechanism involving transmembrane calcium entry into renal juxtaglomerular cells through stretch-activated cation channels. It remains to be clarified in this context whether calcium influx into juxtaglomerular cells directly inhibits renin secretion via the resulting increase of cytosolic calcium concentration (cf. [7]) or whether calcium entry across the plasma membrane is required to refill depleted calcium stores within these cells [10].

Taken together, our findings are consistent with the hypothesis that the baroreceptor control of renin secretion is maintained through interaction between locally released NO providing a tonic stimulus for renin release and a pressure-regulated transmembrane calcium influx into renal juxtaglomerular cells. Moreover, our results also suggest that changes in the calcium sensitivity of these cells are not involved in the pressure control of renin secretion.

Acknowledgements. This study was financially supported by a grant of the Deutsche Forschungsgemeinschaft (Ku 859/2-1).

\section{References}

1. Antonipillai I, Horton R (1985) Role of extra- and intracellular calcium and calmodulin in renin release from rat kidney. Endocrinology 117:601-606

2. Barayas $\mathbf{L}$ (1979) Anatomy of the juxtaglomerular apparatus. Am J Physiol 236:F333-F343

3. Davis MJ, Meininger GA, Zawieja DC (1992) Stretch-induced increases in intracellular calcium of isolated vascular smooth muscle cells. Am J Physiol 263 : H1292-H1299

4. Fray JCS (1976) Stretch receptor model for renin release with evidence from perfused rat kidney. Am J Physiol 231:936944

5. Fray JCS, Park CS (1979) Influence of potassium, sodium, perfusion pressure, and isoprenaline on renin release induced by acute calcium deprivation. J Physiol (Lond) 292:363-372

6. Gardes J, Poux JM, Gonzales MF, Alhenc-Gelas F, Menard J (1992) Decreased renin release and constant kallikrein secretion after injection of L-NAME in isolated perfused rat kidney. Life Sci 50:987-993

7. Hackenthal E, Paul M, Ganten D, Taugner R (1990) Morphology, physiology, and molecular biology of renin secretion. Physiol Rev 70:1067-1116

8. Hellam DC, Podolsky RJ (1969) Force measurements in skinned muscle fibres. J Physiol (Lond) 200:807-819

9. Ito S, Johnson CS, Carretero OA (1991) Modulation of angiotensin II-induced vasoconstriction by endothelium-derived relaxing factor in the isolated microperfused rabbit afferent arteriole. J Clin Invest 87:1656-1663

10. Kurtz A, Penner R (1989) Angiotensin II induces oscillations of intracellular calcium amd blocks inward rectifying potassium current in mouse renal juxtaglomerular cells. Proc Natl Acad Sci USA 86:3423-3427

11. Kurtz A, Pfeilschifter J, Hutter A, Bührle C, Nobiling R, Taugner R, Hackenthal E, Bauer C (1986) Role of protein kinase $\mathrm{C}$ in inhibition of renin release caused by vasoconstrictors. Am J Physiol 250:C563-C571

12. Kurtz A, Skott O, Chegini S, Penner R (1990) Lack of direct evidence for a functional role of voltage-operated calcium 
channels in juxtaglomerular cells. Pflügers Arch 416:281287

13. Lückhoff A, Busse R (1990) Calcium influx into endothelial cells and formation of endothelium-derived relaxing factor is controlled by the membrane potential. Pflügers Arch 416:305-311

14. Meininger GA, Davis MJ (1992) Cellular mechanisms involved in the vascular myogenic response. Am J Physiol 263:H647-H659

15. Münter M, Hackenthal E (1991) The participation of the endothelium in the control of renin release. J Hypertens 9 [Suppl]:S236-S237

16. Murad F, Mittal CK, Arnold WP, Katsuki S, Kimura H (1978) Guanylate cyclase: activation by azide, nitrocompounds, nitric oxide, and hydroxyl radical and inhibition by hemoglobin and myoglobin. Adv Cyclic Nucleotide Res 9:145-157

17. Naess PA, Christensen G, Kirkeboen K, Kiil F (1993) Effect on renin release of inhibiting renal nitric oxide synthesis in anaesthetized dogs. Acta Physiol Scand 148:137-142

18. Palmer RMJ, Ferrige AG, Moncada S (1987) Nitric oxide release accounts for the biological activity of endothelium-derived relaxing factor. Nature 327:524-526

19. Persson PB, Baumann JE, Ehmke H, Hackenthal E, Kirchheim HR, Nafz B (1993) Endothelium-derived NO stimulates pressure-dependent renin release in conscious dogs. Am J Physiol 264:F943-F947
20. Scholz H, Kurtz A (1992) Disparate effects of calcium channel blockers on pressure dependence of renin secretion and flow in the isolated perfused rat kidney. Pflügers Arch 421:155162

21. Scholz H, Kurtz A (1993) Involvement of endothelium-derived relaxing factor in the pressure control of renin secretion from isolated perfused kidney. J Clin Invest 91:1088-1094.

22. Scholz H, Kaissling B, Inagami T, Kurtz A (1991) Differential response of renin secretion to vasoconstrictors in the isolated perfused rat kidney. J Physiol (Lond) 441:453-468

23. Schricker K, Kurtz A (1993) Liberators of NO exert a dual effect on renin secretion from isolated mouse renal juxtaglomerular cells. Am J Physiol 265:F180-F186

24. Schurek HJ, Alt J (1981) Effect of albumin on the function of perfused rat kidney. Am J Physiol 240:F569-F576

25. Taugner R, Bührle CP, Hackenthal E, Mannek E, Nobiling $R$ (1984) Morphology of the juxtaglomerular apparatus and secretory mechanisms. In: Berlyne GM, Giovanetti S (eds) Contributions of nephrology, vol 43. Karger, Basel, pp 76101

26. Vandongen R, Peart WS (1974) Calcium dependence of the inhibitory effect of angiotensin on renin secretion in the isolated perfused kidney of the rat. Br J Pharmacol 50:25-29 